\title{
FORMULATION DEVELOPMENT AND RELEASE STUDIES OF ZIDOVUDINE SUPPOSITORIES
}

\author{
N Santhi Priya*, CH Swaroop Reddy, CH Gowtham Sai, G Madhusudana Rao, G Lakshman Reddy, \\ M Santhosh Aruna \\ Department of Pharmaceutics, Chalapathi Institute of Pharmaceutical Sciences, Lam, Guntur, A.P., India \\ *Corresponding Author's Email: santhipriyampharm@gmail.com
}

Received 12 March 2015; Review Completed 07 April 2015; Accepted 02 May 2015, Available online 15 May 2015

\begin{abstract}
:
The present manuscript deals with the study to formulate and evaluate suppository for the successful delivery of Zidovudine through rectal administration. Zidovudine has tendency to cause gastric ulcer making it necessary to explore safer routes of its administration. Melt Fusion method was used for the preparation of suppositories using glycerogelatin and Emulsified glycerogelatin as suppository base. The prepared suppositories were evaluated for their visual characteristics, physicochemical properties like dimensions, weight variation, melting time, disintegration time, drug content and in-vitro drug release characteristics. The release was found to be greater in emulsified suppositories with satisfactory disintegration time.
\end{abstract}

Keywords: suppository, Fusion method, Zidovudine

\section{INTRODUCTION:}

In the recent years a logic treatment alternative for the patients who cannot tolerate the oral administration has been utilized for the concurrent minimization of the gastro intestinal disorders caused by local anesthetics, anti haemerrhoidal agents, anti anemic agents, anti fungal and anti bacterial agents, anti asthmatic agents , anti psychotic agents and a majority of the natural and synthetic drugs. Rectal route of administration is especially used for infants and children who have the difficulty in swallowing the dosage forms through oral route. ${ }^{1}$

A suppository is a medicated solid dosage form generally intended for use in the rectum, vagina, and to lesser extent, the urethra. Rectal and urethral suppositories usually employs vehicles that melt of soften at body temperature, whereas vaginal suppositories sometimes called pessaries are also made as compressed tablets that disintegrate in the body fluids ${ }^{2}$ Bases acts as the vehicles or carriers of drugs. A variety of substances has been as suppository bases from the commencement of the history of suppository. Their use was governed by the factor of their availability rather than scientific approach. These bases play an important role in release of medication they hold and therefore availability of drug.

Zidovudine (ZDV), is an important drug used for treatment of HIV infection. It belongs to the family of nucleoside analogue reverse transcriptase inhibitors (NRTIs) The effectiveness of ZDV in the treatment of HIV infection is due to its selective affinity for HIV reverse transcriptase as opposed to human DNA polymerases. Since HIV is capable of mutating and thus of developing resistance to the drug. Zidovudine is an FDA approved drug for clinical use in the treatment of adults and children with HIV infections or including with the combination of other anti viral agents. This drug is typically administered in the form of tablets, capsule and an oral solution. The drug has a short half life of about 3 hours and it necessitates the frequent administration. In order to over the drug resistance the present research work deals with the development of suppositories by incorporating zidovudine.

II. MATERIALS AND METHODS :

1. Materials: Zidovudine was procured as a gift sample from Hetero Labs, Hyderabad. All other chemicals and solvents were of analytical grade and used as procured.

\section{Experimental methodology:}

\section{A] Calibration of the suppository mould: ${ }^{4}$}

Mould calibration was performed .Each mould of $1 \mathrm{gm}$ capacity was calibrated before the actual preparation by a set of blank suppositories containing the molten base alone. The product is weighed and the mean weight is taken as the true capacity of the suppository mould. The 
calibration procedure is repeated before every suppository formulations preparation. The calibrated mould capacities ranged from 1 to $2 \mathrm{gms}$.

\section{B] Preparation of suppositories: ${ }^{5}$}

Melt Fusion method: Drug displacement values of the bases used were first determined and the amount of drug required was calculated. The drug powder was passed through a mesh sieve of $100 \mu \mathrm{m}$ prior to its incorporation into the base. This method involves first melting the suppository base, and then dispersing or dissolving the drug in the melted base. The mixture is removed from the heat and poured into a prelubircated suppository mold. When the mixture has congealed, the suppositories are removed from the mold. Tween- 80 was incorporated in the formulation to enhance the release of the drug from the formulation. The compositions of the formulation batches were given in the table 1

Table1: Formulation table of zidovudine suppositories (All values are in percentages)

\begin{tabular}{|l|c|c|c|c|c|c|}
\hline S.N & INGREDIENTS & F1 & F2 & F3 & F4 & F5 \\
\hline 1 & Zidovudine & 1 & 1 & 1 & 1 & 1 \\
\hline 2 & Glycerin & 70 & 60 & 50 & 70 & 70 \\
\hline 3 & Gelatin & 10 & 10 & 10 & 10 & 10 \\
\hline 4 & Purified water & 20 & 20 & 20 & 20 & 20 \\
\hline 5 & Tween80 & - & - & - & 1 & 2 \\
\hline
\end{tabular}

\section{C] Evaluation of zidovudine suppositories:}

Physical Dimension ${ }^{7}$ The width and length of randomly selected suppositories were measured.

Weight Uniformity About 20 suppositories were taken and the average weight was determined. Not more than two individual suppositories should deviated by $10 \%$.

Crushing Strength' ${ }^{9}$ The crushing strength was determined for measuring fragility or brittleness of suppositories, which assessed the suppositories whether they would be able to withstand the hazards of packing, transporting and normal handling are not.

\section{Drug Content Uniformity ${ }^{10}$}

Uniformity of drug content was confirmed by analyzing the drug content in equal batch after dissolving the suppositories in $0.1 \mathrm{~N} \mathrm{NaOH}$ and the drug content was determined at $450 \mathrm{~nm}$.

The results were tabulated in Table- 3

\section{In Vitro Drug Release Studies ${ }^{6}$}

The dissolution of Zidovudine was studied the using USPXXI dissolution apparatus employing basket stirrer. Zidovudine suppositories were placed dissolution medium contain $0.1 \mathrm{~N} \mathrm{NaOH}$ solution. The rpm was adjusted to 50 and a temperature of $37^{\circ} \mathrm{c}$ was maintained throughout the experiment. A $5 \mathrm{ml}$ of sample was withdrawn at various time intervals and diluted with $0.1 \mathrm{~N} \mathrm{NaOH}$ The volume of the dissolution medium was kept constant by replacing the withdrawn volume of the sample with equal volume of fresh dissolution medium maintained at the same temperature. A minimum of triplicate release rate determinations were made for each suppository preparation. and analyzed using UV spectrometer. The results of the drug release were given in Table-4

\section{RESULTS AND DISCUSSION:}

Vaginal suppositories of zidovudine, an antiretroviral drug, were prepared by fusion method using Glycero- gelatin and emulsified glycerogelatin as bases .The prepared suppositories were evaluated for appearance, weight variation ,drug content uniformity, liquefaction/softening time, invitro dissolution. The previously calibrated moulds (1gm capacity)were used for the preparation. The calibrated mould capacities displacement values ranged from 0.95 to $1.02 \mathrm{~g}$. All the suppositories were free from cracks and fissures by appearance. All the longitudinal sections of the suppositories were identified clear and plain. Also the prepared suppositories were evaluated for weight uniformity and the results are given in table. The percentage deviations from the mean weights of all batches were found to be within the prescribed limits (mean weight \pm 5 to $\pm 7.5 \%$ ) as per Indian pharmacopoeia. The drug content was found to be in the range of 97 to 99\%.This was also found to be within the limits. The standard deviation values indicated uniform drug content present within the prepared suppositories. The softening time is the time for which the suppositories withstand the body temperature at $37^{\circ} \mathrm{C}$.The disintegration range was observed to be 4 to $5 \mathrm{~min}$, but the emulsified medicated suppositories exhibits no liquefaction at that temperature. Invitro dissolution studies on the designed formulations were carried out in pH7.4 phosphate buffer and the various dissolution parameters were determined. The results obtained are shown in Table and the dissolution profiles were shown in figures. The data reveals that Glycero-gelatin suppositories(F1-F3 released zidovudine upto $83-87 \%$ and the emulsified glycerogelatin suppositories(F4-F5) released the drug upto $90 \%$.As the emulsifier concentration is increased the drug release was decreased in emulsified glycero-gelatin suppositories whereas in glycerogelatin suppositories the drug release was decreased by the increase of glycerin composition ,in case the release rate decreases because of the high molecular weight and the complex polymer structure of gelatin. 
Table 3: Physicochemical evaluation of suppositories

\begin{tabular}{|c|c|c|c|c|c|c|}
\hline $\begin{array}{l}\text { Formulation } \\
\text { Code }\end{array}$ & $\begin{array}{l}\text { Crushing } \\
\text { strength(gm) }\end{array}$ & $\begin{array}{l}\text { Drug content } \\
\text { \% } \pm \text { SD }\end{array}$ & $\begin{array}{l}\text { Weight } \\
\text { uniformity(gm) }\end{array}$ & $\begin{array}{l}\text { Physical } \\
\text { lenghth(cm) }\end{array}$ & $\begin{array}{l}\text { Dimension } \\
\text { width(cm) }\end{array}$ & $\begin{array}{l}\text { Disintegration } \\
\text { time(min) }\end{array}$ \\
\hline F1 & $500 \pm 0.18$ & $97.99 \pm 0.89$ & 0.850 & 1.813 & 0.890 & 4.08 \\
\hline F2 & $150 \pm 0.23$ & $98.56 \pm 0.12$ & 0.858 & 1.811 & 0.888 & 5.07 \\
\hline F3 & $250 \pm 0.45$ & $99.64 \pm 0.88$ & 0.844 & 1.813 & 0.889 & 5.00 \\
\hline F4 & $450 \pm 0.24$ & $99.89 \pm 0.74$ & 0.852 & 1.814 & 0.898 & 5.62 \\
\hline F5 & $500 \pm 0.21$ & $99.06 \pm 0.15$ & 0.700 & 1.814 & 0.899 & 4.89 \\
\hline
\end{tabular}

Table4: Drug release profile of zidovudine suppositories

\begin{tabular}{|l|l|l|l|l|l|}
\hline TIME & \multicolumn{5}{|c|}{ \% DRUG RELEASED } \\
\hline & F1 & F2 & F3 & F4 & F5 \\
\hline 5 & 48.84 & 45.5 & 42.15 & 40.48 & 49.05 \\
\hline 10 & 65.57 & 53.86 & 58.86 & 50.52 & 52.21 \\
\hline 15 & 67.24 & 65.57 & 65.58 & 65.27 & 68.55 \\
\hline 30 & 68.92 & 70.50 & 67.24 & 67.24 & 70.25 \\
\hline 45 & 72.96 & 75.61 & 68.92 & 70.50 & 75.52 \\
\hline 60 & 75.52 & 77.28 & 75.21 & 72.26 & 79.44 \\
\hline 90 & 83.92 & 80.63 & 82.30 & 85.30 & 85.69 \\
\hline 120 & 83.91 & 84.23 & 84.21 & 87.52 & 90.45 \\
\hline
\end{tabular}

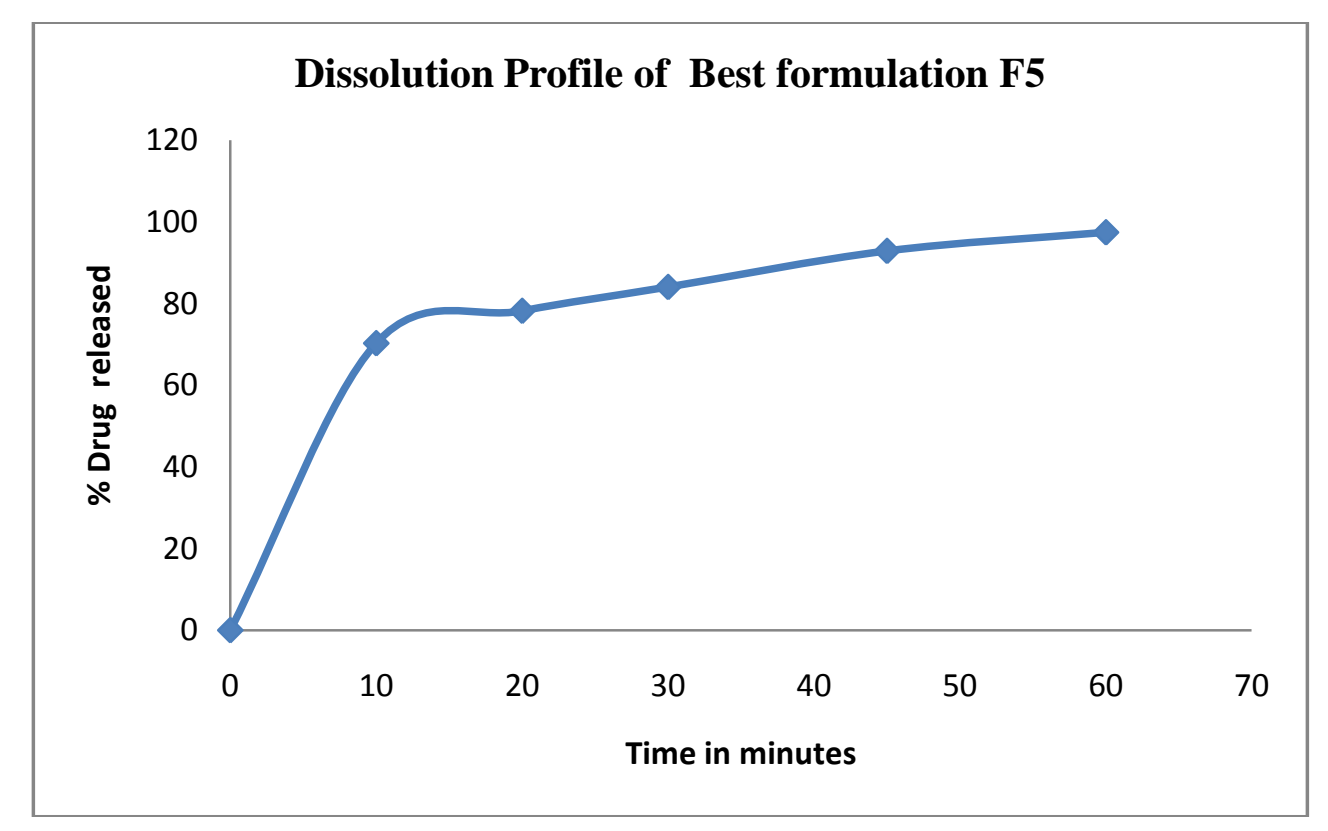

Figure 1: Dissolution Profile of Best formulation F5

\section{CONCLUSION:}

The present study indicates that it is possible to design vaginal suppositories for the drug Zidovudine, employing the water soluble polymeric base like Glycero-gelatin base. Also this study identifies that by the addition of emulsifiers the drug release profile was modified when compared to Non-emulsified Zidovudine Suppositories. The drug release is nearly first order. However, this study needs Invivo studies in the animal models to ascertain the relative bioavailability of zidovudine suppositories as a promising platform as dosage form.

\section{ACKNOWLEDGEMENTS:}

The support of Chalapathi institute of pharmaceutical sciences in providing all the Laboratory and technical support is gratefully acknowledged. 


\section{REFERENCES:}

1. Jain NK, "Progress in controlled and Novel drug delivery system" Ist edition, CBS Publication;2008,P. 96-118.

2. Swarbrick JC, "Encyclopaedia of pharmaceutical technology" Vol-I, 2nd edition, 2009;P.32- 940.

3. Onyeji CO, Adebayo AS and Babalola CP, Effects of absorption enhancers in chloroquine suppository formulation 1: I In vitro release characteristics, Eur. J. Pharm. Sci., 1999, 9: $131-136$.

4. Rejman F,"Use of Roinal suppositories in patients with ano rectal complaints Duodecim”, 1962, 727-729.

5. Varshney, H.M, and Tanwar, Y.S., "Designing, Release Characteristics and In vitro Evaluation of Flurbiprofen Sodium Suppositories", International Journal of Pharmaceutical and Clinical Research, 2009, 1, 31-34.

6. Ramadan, A.A, "Preparation, characterization and in-vivo evaluation of double phased mucoadhesive suppsoitories containing diclofenac in rats", J. Appl. Sci. Res., 2012, 8, 746-752.

7. Gold, M., Ve Puri, M., Block, L., "Suppository Development and Production" in Pharmaceutical Dosage Forms: Disperse Systems Liberman, H.A. (Ed.), Informa Healthcare, New York, 2008, P. 472-473.

8. Coben, L.J., and Lieberman, H.A., "Suppositories" in The theory and practice of industrial pharmacy, Lachman, L., and Lieberman, H.A.(editors.), CBS Publishers and Distributors, New Delhi, 2009, P. 586-587.

9. Varshney HM, Tanwar YS, Acta Pharmaceutica Sciencia,2010; 52: 129-136.

10. Baria A. H., Patel R. P, Suthar A. M., and Parmar R. B., "Formulation Development and Evaluation of Sustained Release Aceclofenac Suppository", International Journal of Pharmaceutical Sciences and Drug Research,2009, 1(2): 7173. 